\title{
Entrapment of toxic anions using calixarenes framework
}

\begin{abstract}
Calixarenes are excellent macro cyclic platforms that can be functionalized with numerous organic moieties to show cooperative binding towards anions. Their characteristic structural features with the ease of functionalization offers the way to tune the size of receptor cavity. This has led to finely tune the binding site and central hydrophobic cavity for the specified anions. Calixarene based systems provide prospective commercial applicability's in anion sensing and helps in understanding complex binding interaction. Intending to decipher the detailed insight of anion-calixarene binding, the present review discusses the reports of calixarene compounds tested for their toxic anionic recognition ability.
\end{abstract}

Keywords: calixarene, calixpyrrole, anion recognition, binding interactions, toxic anionic
Volume 3 Issue 6 - 2017

\author{
Mohd Athar,' Anita Kongor, ${ }^{2}$ Manthan \\ Panchal, ${ }^{2}$ Prakash C Jha, ${ }^{3}$ Vinod Jain ${ }^{2}$ \\ 'School of Chemical Sciences, Central University of Gujarat, \\ India \\ 2Department of Chemistry, Gujarat University, India \\ ${ }^{3}$ Centre for Applied Chemistry, Central University of Gujarat, \\ India
}

Correspondence: Mohd Athar, School of Chemical Sciences, Central University of Gujarat, Gandhinagar 382030, Gujarat. India, Email mathar93@gmail.com

Received: October 30, 2017 | Published: November 30, 2017

\section{Introduction}

Anion binding is a key process in many biological and chemical processes and the design of synthetic molecular receptors which bind specifically to anions is an area of current importance..$^{1-4}$ There are numerous reasons to heighten up this interest. One of the open challenge for modern chemist in anion recognition chemistry is selective recognition of anions. In this course, many synthetic receptors have been developed owing to the coordination ability of the appended substituents. However, the development of anionic receptor is comparatively slow than cationic receptor due to the exceptional properties of anions. ${ }^{5}$ These include, delocalised nature of negative charge over atoms, larger size, diverse geometry of anions (spherical, linear, tetrahedral or octahedral), $\mathrm{pH}$ dependence and salvation. ${ }^{6}$ Release of anion through various commercial applications viz. nucleophiles, bases, catalysts, redox reagents can pose unwanted environmental toxicities. ${ }^{6}$ Hence, entrapment of anions through receptors is pivotal that enables the separation using the coordination mechanism. Intriguingly, anions are also essential for the biological relevant metabolic functions therefore molecules that mimicks the anion binding are therapeutically pertinent for treating cystic fibrosis, cancer and Alzheimer's diseases. ${ }^{7}$ There is, therefore, intense effort being devoted to the problem of anion complexation and recognition using macro cyclic receptors based on calixarenes, cyclophane, steroid, pyrroles, and other charged and non-charged macro cyclic receptors are reported so far. ${ }^{8-10}$

Calixarenes are the macro cyclic architectures with upper/lower rim and a characteristic central cavity. ${ }^{11-14}$ Calix[n]arenes was found as easy to make anion binding agents due to adoption of range of conformations and capability of being functionalized at both upper and lower rim. ${ }^{15}$ The main feature of this new macro cycle is its ability to bind selectively with various anions, cation and neutral analytes (Figure 1). Among calix architectures, there have been many theoretical and experimental studies on calixpyrrole. ${ }^{16-18}$ The binding to anions can be achieved through protonated $\mathrm{N}$-containing macro cycles. Owing to partially filled with $\mathrm{NH}$ protons, Hexacyclen (Nitrogen analogy of crown ether) or azacorand type macro cycle cavity selectively able to bind with the anions. ${ }^{19}$ Moreover, the appended amide and urea substituent's have engendered significant anion binding properties to the calixarenes. For instance, montecarlo simulations on 1,3-difunctionalised bis (urea)calix ${ }^{4}$ arenes with long flexible butyl spacers displayed that fluoride binds with the greatest affinity in the centroid of the cleft formed by NH bonds. ${ }^{20}$ Subsequently, Liu, synthesized neutral anion receptors optimizing the suitable distance between the binding site, which demonstrate selectivity against dicarboxylate anions. ${ }^{21}$ It was further articulated that increased acidity of $\mathrm{NH}$ protons in urea $(\mathrm{pKa}=26.9)$ and thioarea $(\mathrm{pKa}=21.0)$ was responsible for the enhanced complexation ability of such receptors. ${ }^{22}$

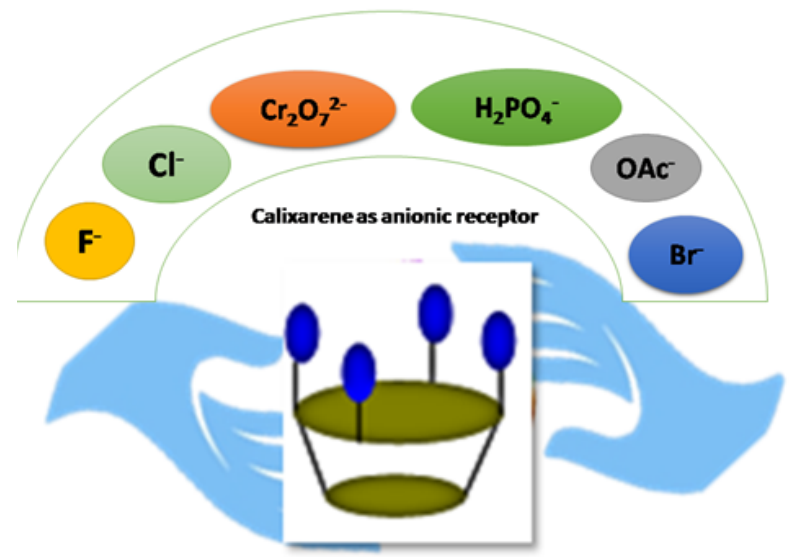

Figure I Anion binding diversity of calixarenes.

\section{Anion binding receptor requirement}

In contrast to cations, anions are relatively larger in size therefore require receptors of considerably greater size than cations (Table 1). This size match between anion and host cavity for complementarity and topology selectivity is crucial. Prevailing interactions which takes place in anion binding are: hydrogen bonding, ion-dipole, ion-ion and 
van der Waals interactions. Moreover, anions have high free energies of solvation and hence they can compete more effectively with the medium. The anion binding specificity arises from the preorganized placement of complementary binding sites. As such, the various anionic acceptors have been exercised.

Table I Size of the anion that corresponds to the size of the calix binding site

\begin{tabular}{ll}
\hline Anion & Diameter (A) \\
\hline $\mathrm{Na}^{-}$ & 4.4 \\
$\mathrm{~F}-$ & 2.66 \\
$\mathrm{Cl}^{-}$ & 3.62 \\
$\mathrm{Br}$ & 3.9 \\
$\mathrm{~F}$ & 4.32 \\
\hline
\end{tabular}

\section{Binding interaction types}

In particular, many anions have diverse geometries that offer a possible route to the development of shape-selective anion receptors. Although, the non-covalent interactions involved in anion coordination are hydrogen bonds, electrostatic interactions, metal coordination, Anion- pi interactions and Lewis acid interactions, hydrophobicity and combination of these forces. ${ }^{8}$ Organic based receptors have been developed which rely solely on hydrogen bond donors such as amides. ${ }^{23}$ Typically, the indispensable binding interactions can be classical non-covalent ranging from $\mathrm{H}$-bonding to cation- $\pi,^{24} \pi-\pi$ stacking ${ }^{25}$ or anion- $\pi .^{26}$ However, its definition is also extended to interactions involving aromatic moieties, ${ }^{27}$ weak $\mathrm{C}-\mathrm{H}$ hydrogen bonds ${ }^{28,29}$ or interactions between halogen atoms and lewis bases. ${ }^{30-33}$ The lewis acid-base type of interaction also termed as $\sigma$ hole bonds represent an important and emerging class of non-covalent bonding. Loss of electronic charge at the covalent bonds results the generation of positive electrostatic potential which thereby act as lewis acid centre. ${ }^{34,35}$ However, halogen,${ }^{36}$ pnictogen ${ }^{37}$ or chalcogen ${ }^{38}$ are the most widely used lewis base centres forming the $\sigma$ - hole bonds. More recently, $\sigma$-hole bonds have been recognized and described as pivotal to generate new family of anion receptors that can be selective especially for spherical and linear anions. ${ }^{39,40}$

\section{Calixarenes derivatives as anionic host}

Unmodified calixarene frameworks show no affinity for anionic guests, functionalized calixarenes have been shown to be capable of binding anions. ${ }^{41-43}$ Calixarenes and their derivatives interact via these non-covalent interactions with certain anions like phosphate, cyanide, chloride, fluoride, etc. and find applications in material chemistry. ${ }^{44} 48$ Some instances of previous works are, Gale reported the synthesis of fluorescent anthracene- calyx ${ }^{4}$ pyrrole conjugates which can detect the presence of anions like (e.g. $\mathrm{F}^{-}, \mathrm{Cl}^{-}, \mathrm{H}_{2} \mathrm{PO}_{4}^{-}$) through quenching of their fluorescence. ${ }^{49}$ Anion-binding properties of a new calix [4]pyrrole with flexiblecatechol-derived diether strap on one side was reported by Samanta. which showed different preferences of binding towards dihydrogenphosphate, acetate ions and fluoride ions. ${ }^{50}$ The extraction of dichromate anions were reported by Yilmaz. using new calixarene based extractantsynthesizedfrom from 5,11,17,23-tetra-tert-butyl25,27-bis(chlorocarbonyl-methoxy)-26,28-dihydroxycalix [4] arene by treatmentwith isoniazid in the presence of pyridine. ${ }^{51}$ Another synthetic receptors for monocharged anions using new p-tert-butylthiacalix ${ }^{4}$ arenes linked with phenylurea fragments was reported by Stoikov et al. ${ }^{52}$ The compound, phenylurea-equipped p-tert-butylthiacalix [4]arenes was found to show interactions with for fluoride, acetate or dihydrogenphosphate anions depending on the conformation of the macro cycle (cone, 1,3-alternate) and the number of substituents. Chromogenic anion recognition abilities in case of fluoride, acetate and dihydrogenphosphate ions was reported by Kumar et al..$^{53}$ by anion complexation induced $\sigma$-extended conjugation in iminoazophenol appended calix[4]arene/thiacalix ${ }^{4}$ arene derivatives.

\section{Conclusion}

To sum up, the use of various calixarenes framework have opened a broader gateway for researchers working in the field of anion sensing applications. Non-covalent coordination of calix based compounds has received immense attention realizing its inherent properties exemplified by the hydrophobic nature of the cavity. A better understanding of calix-anion complexation using theoretical repositories based on computational work offers a rationalized perceptiveness to the current subject. Thus, the promises that calixarenes heralds in the field of anion binding is a destined area with respect to contemporary chemistry.

\section{Acknowledgements}

This work was supported by Department of Science \& Technology (DST), New Delhi under INSPIRE-JRF grant awarded to Mohd. Athar and Anita Kongor. The authors also acknowledge Central University of Gujarat-Gandhinagar (CUG) and Gujarat University for providing basic infrastructure and facilities.

\section{Conflict of interest}

The author declares no conflict of interest.

\section{References}

1. Gale PA, Sessler JL, Král V, et al. Calix [4] pyrroles: old yet new anion-binding agents. Journal of the American Chemical Society. 1996;118(21):5140-5141.

2. Lehn JM. Supramolecular chemistry: receptors, catalysts, and carriers. Science. 1985;227(4689):849-857.

3. Beer PD. Anion selective recognition and optical/electrochemical sensing by novel transition-metal receptor systems. Chemical Communications. 1996;(6):689-696.

4. Bhat HR, Jha PC. Selective Complexation of Cyanide and Fluoride Ions with Ammonium Boranes: A Theoretical Study on Sensing Mechanism Involving Intramolecular Charge Transfer and Configurational Changes. J Phys Chem A. 2017;121(19):3757-3767.

5. ONeil EJ, Smith BD. Anion recognition using dimetallic coordination complexes. Coordination chemistry reviews. 2006;250(23-24):30683080 .

6. Matthews SE, Beer PD. Calixarene-based anion receptors. Calixarenes. 2001:421-439.

7. Antonisse MM, Reinhoudt DN. Neutral anion receptors: design and application. Chemical Communications. 1998;4:443-448.

8. Prados P, Quesada R. Recent Advances in Macrocyclic and MacrocyclicBased Anion Receptors. Supramolecular Chemistry. 2008;20(1-2):201216 . 
9. Bisson AP. Recognition of Anions through NH $\pi$ Hydrogen Bonds in a Bicyclic Cyclophane-Selectivity for Nitrate. Angewandte Chemie International Edition. 1997;36(21):2340-2342.

10. Athar M, Lone MY, Jha PC. Assessing calix [n] arene as drug carriers for second generation tyrosine kinase inhibitors by theoretical methods. Journal of Molecular Liquids. 2017;247:448-455.

11. Jain V, Kanaiya P. Chemistry of calix [4] resorcinarenes. Russian Chemical Reviews. 2011;80(1):75-102.

12. Mandalia VK. The Chemistry of Callxpyrroles. Heterocycles. 2007;71(6):1261-1314.

13. Kongor AR, Mehta VA, Modi KM, et al. Calix-Based Nanoparticles: A Review. Top Curr Chem (Cham). 2016;374(3):1-46.

14. Mehta V, Panchal U, Jain VK, et al. The Chemistry of Nascent Oxacalix [n] hetarene $(n \geq 4)$ : A Review. Current Organic Chemistry. 2015;19(12):1077-1096.

15. Athar M, Lone MY, Jha PC. Investigation of structure and conformational equilibrium of Oxacalix [4] arene: A density functional theory approach. Journal of Molecular Liquids. 2017;237:473-483.

16. Wu YD, Wang DF, Sessler JL. Conformational features and anionbinding properties of calix [4] pyrrole: a theoretical study. J Org Chem. 2001;66(11):3739-3746.

17. Sessler JL, Gross DE, Cho WS, et al. Calix [4] pyrrole as a chloride anion receptor: solvent and countercation effects. J Am Chem Soc. 2006;128(37):12281-12288.

18. Pichierri F. Effect of fluorine substitution in calix [4] pyrrole: A DFT study. Journal of Molecular Structure: Theochem. 2008;870(1):36-42.

19. Cullinane J, Gelb RI, Margulis TN. Hexacyclen complexes of inorganic anions: bonding forces, structure, and selectivity. Journal of the American Chemical Society. 1982;104(11):3048-3053.

20. McDonald NA, Duffy EM, Jorgensen ML. Monte Carlo investigations of selective anion complexation by a bis (phenylurea) p-tert-butylcalix [4] arene. Journal of the American Chemical Society. 1998;120(20):51045111.

21. Liu SY, Bing He Y, Wu JL, et al. Calix [4] arenes containing thiourea and amide moieties: neutral receptors towards $\alpha, \omega$-dicarboxylate anions. Organic \& biomolecular chemistry. 2004;2(11):1582-1586.

22. Qureshi N, Dimitri S, Yufit, et al. Hydrogen bonding effects in anion binding calixarenes. Cryst Eng Comm. 2014;16(36):8413-8420.

23. Newcomb M, Madonik AM, Blanda MT, et al. Macrocycles containing tin. Tin-119 NMR studies of chloride binding by Lewis acidic tin compounds. Organometallics. 1987;6(1):145-150.

24. Ma JC, Dougherty DA. The cation $-\pi$ interaction. Chemical reviews. 1997;97(5):1303-1324.

25. Schneider HJ. Binding mechanisms in supramolecular complexes. Angew Chem Int Ed Engl. 2009;48(22):3924-3977.

26. Frontera A, Gamez P, Mascal M, et al. Putting anion- $\pi$ interactions into perspective. Angewandte Chemie International Edition. 2011;50(41):9564-9583.

27. Meyer EA, Castellano RK, Diederich F. Interactions with aromatic rings in chemical and biological recognition. Angewandte Chemie International Edition. 2003;42(11):1210-1250.

28. Desiraju G, Steiner T. The Weak Hydrogen Bond. USA: Oxford University Press; 1999.

29. Steiner T. The hydrogen bond in the solid state. Angew Chem Int Ed Engl. 2002;41(1):48-76.
30. Legon AC. The halogen bond: an interim perspective. Physical Chemistry Chemical Physics. 2010;12(28):7736-7747.

31. Scholfield MR, Crystal MVZ, Megan C, et al. Halogen bonding (Xbonding): A biological perspective. Protein Science. 2013;22(2):139152.

32. Erdelyi M. Halogen bonding in solution. Chemical Society Reviews. 2012;41(9):3547-3557.

33. Parisini E, Metrangolo P, Pilati T, et al. Halogen bonding in halocarbonprotein complexes: a structural survey. Chem Soc Rev. 2011;40(5):22672278 .

34. Politzer P, Murray JS, Clark T. Halogen bonding and other $\sigma$-hole interactions: a perspective. Physical Chemistry Chemical Physics. 2013;15(27):11178-11189.

35. Clark T. $\sigma$-Holes. Wiley Interdisciplinary Reviews: Computational Molecular Science. 2013;3(1):13-20.

36. Metrangolo P, Resnati G. Halogen bonding: a paradigm in supramolecular chemistry. Chemistry-a European Journal. 2001;7(12):2511-2519.

37. Sundberg MR, Ugglaa R, Viñasb C, et al. Nature of intramolecular interactions in hypercoordinate $\mathrm{C}$-substituted 1, 2-dicarba-closododecaboranes with short $\mathrm{P} \cdots \mathrm{P}$ distances. Inorganic Chemistry Communications. 2007;10(6):713-716.

38. Sanz P, Yáñez M, Mó O. The Role of Chalcogen-Chalcogen Interactions in the Intrinsic Basicity and Acidity of $\beta$-Chalcogenovinyl (thio) aldehydes $\mathrm{HC}(\mathrm{X}) \square \mathrm{CH} / \mathrm{CH} \square \mathrm{CYH}(\mathrm{X}=\mathrm{O}, \mathrm{S} ; \mathrm{Y}=\mathrm{Se}, \mathrm{Te})$. Chemistry-A European Journal. 2002;8(17):3999-4007.

39. Cavallo G, Pierangelo M, Tullio P, et al. Halogen bonding:a general route in anion recognition and coordination. Chemical Society Reviews. 2010;39(10):3772-3783.

40. McDowell SA. Sigma-hole cooperativity in anionic [FX $\cdots \mathrm{CH} 3 \cdots \mathrm{YF}]$ (X, Y= Cl, Br) complexes. Chemical Physics Letters. 2014;598:1-4.

41. Beer PD, Gale PA, Hesek D. A neutral upper to lower rim linked bis-calix [4] arene receptor that recognises anionic guest species. Tetrahedron letters. 1995;36(5):767-770.

42. Scheerder J, Johan FJE, Alessandro Casnati, et al. Complexation of halide anions and tricarboxylate anions by neutral urea-derivatized p-tert-butylcalix [6] arenes. The Journal of Organic Chemistry. 1995;60(20):6448-6454.

43. Steed JW, Juneja RK, Atwood JL. A Water-Soluble "Bear Trap" Exhibiting Strong Anion Complexation Properties. Angewandte Chemie International Edition. 1995;33(23-24):2456-2457.

44. Kivlehan F, Wade JM, Humphrey AM, et al. Potentiometric evaluation of calix[4] arene anion receptors in membrane electrodes:phosphate detection. Analytical Chimica Acta. 2007;585(1):154-160.

45. Zhu SS, Staats H, Brandhorst K, et al. Anion binding to resorcinarenebased cavitands: the importance of $\mathrm{C}-\mathrm{H}$...anion interactions. Angew Chem Int Ed Engl. 2008;47(4):788-792.

46. Hong SJ, Yoo J, Kim SH, et al. Beta-vinyl substituted calix[4] pyrrole as a selective ratiometric sensor for cyanide anion. Chem Commun. 2009;2:189-191.

47. Yoon DW, Gross DE, Vincent ML, et al. Real-time determination of chloride anion concentration in aqueous-DMSO using a pyrrolestrapped calixpyrrole anion receptor. Chem Commun. 2009;9:1109-1111.

48. Ballester P. Anion binding in covalent and self-assembled molecular capsules. Chem Soc Rev. 2010;39(10):3810-3830.

49. Miyaji H, Pavel Anzenbacher, Jonathan L Sessler, et al. Anthracenelinked calix[4] pyrroles: fluorescent chemosensors for anions. Chemical Communications. 1999;1999(17):1723-1724. 
50. Samanta R, Sanjeev P, Chaudhuria S, et al. New strapped calyx [4] pyrrole based receptor for anions. Inorganica Chimica Acta. 2011;372(1):281285 .

51. Tabakci M, Shahabuddin Memon, Mustafa Yilmaz, et al. Synthesis and extraction studies of a versatile calix[4]arene-based "Proton-Switchable Extractant" for toxic metals and dichromate anions. Journal of Inclusion Phenomena and Macrocyclic Chemistry. 2003;45(3-4):267-270.
52. Galukhin AV, Konstantin VS, Antipin IS, et al. Phenylurea-Equipped $<\mathrm{i}>$ $\mathrm{p}</ \mathrm{i}>-<\mathrm{i}>$ tert $</ \mathrm{i}>-$ Butylthiacalix [4] Arenes as the Synthetic Receptors for Monocharged Anions. Mendeleev Communications. 2013;23(1):4143.

53. Kumar M, Babu JN, Bhalla V. Azophenol appended (thia) calyx[4] arenes for colorimetric sensing of anions: a complexation induced extended conjugation. Talanta. 2010;81(1-2):9-14. 